\title{
As operações de multiplicação e de divisão nas edições da Segunda Aritmética da série Concórdia
}

\author{
The multiplication and division operations in the editions of the Second Arithmetic of \\ the Concordia Series
}

\author{
Malcus Cassiano Kuhn \\ malcusck@yahoo.com.br
}

Arno Bayer

bayer@ulbra.br

\begin{abstract}
Resumo
$\mathrm{O}$ artigo discute os aspectos pedagógicos e metodológicos relacionados ao ensino da multiplicação e da divisão em duas edições da Segunda Aritmética da série Concórdia, editadas pela Igreja Luterana para suas escolas paroquiais no Rio Grande do Sul, durante a primeira metade do século XX. Em 1900, o Sínodo de Missouri, hoje Igreja Evangélica Luterana do Brasil, iniciou sua missão nas colônias alemãs gaúchas, fundando congregações religiosas e escolas paroquiais. Estas escolas buscavam ensinar a língua materna, a matemática, valores culturais, sociais e religiosos. Baseando-se na história cultural e na análise de conteúdo, verificou-se que, embora a Segunda Aritmética de Otto Goerl apresente uma proposta de estudo das operações de multiplicação e de divisão por 2 até 10 de forma mais contextualizada com práticas socioculturais, as duas aritméticas trazem atividades para o desenvolvimento de habilidades de cálculo mental e de cálculo escrito, com foco nos algoritmos e procedimentos de cálculo das operações de multiplicação e de divisão.
\end{abstract}

Palavras-chave: Multiplicação; Divisão; Segunda Aritmética da Série Concórdia; Ensino da Matemática; Escolas Paroquiais Luteranas.

\begin{abstract}
The article discusses the pedagogical and methodological aspects related to the teaching of the multiplication and of the division in two editions of the Second Arithmetic of the Concordia series, edited by the Lutheran Church for their parochial schools in Rio Grande do Sul, during the first half of the twentieth century. In 1900, the Missouri Synod, today Evangelical Lutheran Church of Brazil, began his mission in the gaucho German colonies, founding religious congregations and parochial schools. These schools sought to teach the mother tongue, the mathematics, cultural, social and religious values. Basing on the cultural history and on the content analysis, it was found that although the Second Arithmetic of Otto Goerl submit a proposal of study of the multiplication and division operations by 2 to 10 more contextualized with socio-cultural practices, the two arithmetical bring activities for the development of skills of mental calculation and of written calculation, focusing on the algorithms and calculation procedures of multiplication and division operations.
\end{abstract}

Keywords: Multiplication; Division; Second Arithmetic of the Concordia Series; Mathematics Teaching; Lutheran Parochial Schools.

\section{Introdução}

Este artigo aborda as operações de multiplicação e de divisão em duas edições da Segunda Aritmética da série Concórdia, editadas pela Igreja Evangélica Luterana do Brasil IELB - e adotadas nas escolas paroquiais luteranas do Rio Grande do Sul - RS, durante a primeira metade do século XX. Trata-se de um estudo qualitativo com aporte na história cultural e na análise de conteúdo. 
Chervel (1990) considera importante o estudo histórico da cultura escolar recebida pelos alunos, buscando-se a compreensão dos elementos que participam da produção/elaboração/constituição dos saberes escolares e, em particular, da matemática escolar e sua história. Essa cultura escolar é definida por Julia (2001) como um conjunto de normas que estabelecem conhecimentos a ensinar e condutas a inspirar, e um conjunto de práticas que permitem a transmissão desses conhecimentos e a incorporação desses comportamentos.

De acordo com Bardin (2011), uma investigação a partir da perspectiva da análise de conteúdo está sempre procurando um texto atrás de outro texto, um texto que não está aparente já na primeira leitura e que precisa de uma metodologia para ser desvendado. A autora sugere três etapas para essa análise de conteúdo: a pré-análise em que se faz a escolha dos documentos e a partir destes, a formulação de objetivos, de hipóteses e de indicadores para análise (unidades de análise e categorias, por exemplo); a exploração dos materiais por meio dos indicadores elaborados; o tratamento dos resultados para interpretação das mensagens e inferências.

A abordagem dos aspectos pedagógicos e metodológicos relacionados ao ensino da multiplicação e da divisão em livros de aritmética utilizados nas escolas paroquiais luteranas gaúchas é realizada por meio de uma caracterização destas escolas e da análise de conteúdo das duas edições da Segunda Aritmética da série Concórdia, com base num instrumento de análise de conteúdo construído com cinco unidades de análise ${ }^{1}$ e suas respectivas categorias, detalhado em Kuhn (2015).

\section{As escolas paroquiais luteranas gaúchas}

Com o início do trabalho missionário do Sínodo Evangélico Luterano Alemão de Missouri, atualmente IELB, no RS, em 1900, além das congregações luteranas, começaram a ser fundadas as escolas paroquiais. De acordo com Kuhn (2015), as escolas paroquiais luteranas estavam inseridas num projeto comunitário que buscava ensinar a língua materna, a matemática, valores culturais, sociais e, principalmente, religiosos.

Para o Sínodo de Missouri, o sucesso da missão passava pela valorização da escola paroquial. Era necessário consolidar um campo religioso e fortalecê-lo investindo na escola, e também influenciar o campo familiar dos seus possíveis fiéis. “A escola paroquial se revelou

\footnotetext{
${ }^{1}$ As cinco unidades utilizadas para o estudo das aritméticas adotadas pelas escolas paroquiais luteranas do RS são: conteúdos ( 7 categorias), aspectos pedagógicos ( 8 categorias), processo de ensino e aprendizagem (6 categorias), recursos didáticos (5 categorias), linguagem e aspectos gráfico-editoriais (4 categorias).
} 
como uma grande benção para o bem e o desenvolvimento da Igreja Luterana. As congregações que mantinham escolas paroquiais, geralmente eram as melhores congregações" (WARTH, 1979, p. 195).

As escolas paroquiais tinham uma responsabilidade para com a comunidade no sentido de, junto e com ela, promover o crescimento e o desenvolvimento pessoal de todos que a compõe, focando, principalmente, a cidadania. Se a escola formasse o ser humano com postura ética e moral exemplar, este poderia promover transformações sólidas em seu contexto social e seria um verdadeiro colaborador na ceara de Deus e para o governo do mundo. As escolas paroquiais luteranas eram assim caracterizadas por Weiduschadt (2007):

\begin{abstract}
As escolas eram organizadas de forma multisseriada. As turmas eram compostas de 20 a 40 alunos. Na maioria das vezes, o pastor da comunidade era, ao mesmo tempo, professor. As escolas funcionavam em forma comunitária, ou seja, a comunidade sustentava a estrutura física e mantinham o professor da escola. O prédio era muitas vezes o mesmo local do templo. A ligação entre a escola e a igreja era importante, porque logo no início da formação das comunidades o ensino doutrinário e pedagógico era ressaltado e sua suplementação implicava questões econômicas e culturais para a implementação. O projeto escolar dentro da comunidade religiosa era marcante, a orientação e a obrigação de os pais enviarem os filhos à escola eram quase obrigatórias, com sanções econômicas e morais, caso não concordassem (WEIDUSCHADT, 2007, p. 166-168).
\end{abstract}

O Sínodo de Missouri também tinha uma preocupação acentuada em relação aos recursos didáticos usados nas escolas paroquiais, pois este material era escasso e a dificuldade era grande em manter um ensino planificado e organizado. Era necessário organizar o currículo das escolas, obter uma autonomia em relação à matriz, e produzir material de acordo com a realidade brasileira. Assim, conforme Weiduschadt (2007, p. 41), "os livros usados nas escolas paroquiais e utilizados pelos alunos foram produzidos pelas instituições religiosas com objetivo de formar e moldar as condutas e as práticas ao fazer a escolarização das comunidades". Dessa forma, por meio dos livros didáticos e dos periódicos, as escolas paroquiais luteranas conseguiram desenvolver uma educação integral cristã em todas as disciplinas, inclusive em matemática. Conforme Lemke (2001), o ensino da Palavra de Deus, através da Bíblia, ficava em primeiro lugar, e as demais disciplinas não eram menos prezadas, mas complementavam a educação para servir no mundo.

\title{
3 A multiplicação e a divisão nas edições da Segunda Aritmética da série Concórdia
}

Os primeiros trinta anos de existência das escolas paroquiais luteranas no RS foram marcados pela carência de materiais didáticos e pela progressiva adoção dos quatro manuais de Büchler, tanto em alemão, quanto em português, para as aulas de matemática. Na revista 
Unsere Schule (ago. 1933, p. 6, tradução nossa), afirma-se que "os livros de aritmética de Büchler (editora Rotermund), são usados na maioria das nossas escolas e que a mesma editora lançou recentemente um novo manual: meu livro de contas, por W. Nast e L. Tochtrop". Porém, na mesma edição, este manual é analisado criticamente, apontando-se a necessidade de um livro com princípios morais e educacionais em concordância com os princípios pedagógicos misourianos e adaptados as condições nacionais.

Por isso, o Sínodo de Missouri começou a produzir seus próprios livros de aritmética na década de 1930. No periódico Unsere Schule, edição de mar./abr. de 1934, faz-se referência aos novos livros de aritmética: “o Sínodo decidiu que será editado neste ano um trabalho completo de aritmética. Os professores Frederico Strelow, Albert Brückmann e Max Öhlwein foram contratados para realizar o trabalho" (UNSERE SCHULE, mar./abr. 1934, p. 14, tradução nossa). Este trabalho completo de aritmética foi a série Ordem e Progresso, pois em edições posteriores, o mesmo periódico faz divulgação da Primeira Aritmética e da Segunda Aritmética desta série.

A edição e a publicação do material didático específico para as escolas paroquiais luteranas gaúchas, com base em princípios morais e educacionais idealizados pela IELB, foram realizadas pela Casa Publicadora Concórdia de Porto Alegre/RS. Para as aulas de matemática, foram publicadas duas séries: a série Ordem e Progresso, lançada na década de 1930, pela divulgação feita na revista Unsere Schule, e a série Concórdia, lançada na década de 1940. Acredita-se que cada série tenha sido composta pela Primeira Aritmética, Segunda Aritmética e Terceira Aritmética. Localizaram-se no Instituto Histórico da IELB em Porto Alegre, a Primeira Aritmética e a Terceira Arithmetica, da série Ordem e Progresso, e duas edições da Segunda Aritmética e uma edição da Terceira Aritmética, ambas da série Concórdia. Como a Primeira Aritmética aborda os números naturais até 100, com ênfase na construção do significado de número e nas operações de adição e de subtração, e as edições da Terceira Aritmética enfatizam as frações ordinárias e decimais, o sistema métrico e a matemática comercial e financeira, o presente estudo se restringe à análise das duas edições da Segunda Aritmética da série Concórdia, as quais priorizam o estudo das operações de multiplicação e de divisão com números naturais.

Uma das edições da Segunda Aritmética da série Concórdia é de autoria de Otto A. Goerl, não tem ano de edição. Como na página 3 é feita a representação de moedas (em cruzeiros) datadas de 1944 a 1947, acredita-se que o livro tenha sido editado logo após esta última data. O livro possui 77 páginas, mas não apresenta sumário. Está dividida em três secções: I - Números de 1 a 100; II - Números de 1 a 1000; III - Números até 10000. A outra

\footnotetext{
${ }^{2} \mathrm{Na}$ década de 1930, a IELB começou a publicar um periódico pedagógico dirigido às suas escolas paroquiais, chamado Unsere Schule (Nossa Escola).
} 
edição da Segunda Aritmética da série Concórdia analisada, não tem autoria identificada e foi editada em 1948. A obra possui 96 páginas e também não apresenta sumário. Suas principais unidades de estudo são: numeração 1 - 1000; os números até 10000; números além de 10000.

Conforme Lindemann (1888, p. 51, tradução nossa), "nos primeiros anos de escola era suficiente que as crianças compreendessem os números até 1000 e executassem cálculos envolvendo as quatro operações. Nos anos seguintes, deveriam aprender as quatro operações com todos os números e também os números decimais”. No programa das aulas de cálculo para os quatro anos obrigatórios, a partir de 1900, Rambo aponta que:

No segundo ano, aprendia-se a multiplicação e a divisão desde números pequenos e simples, até grandes e complexos. O egresso do segundo ano, portanto, encontravase apto para resolver todos os problemas práticos no âmbito das quatro operações. Complementava-se também a fixação da pequena tabuada ${ }^{3}$ e intensificava-se a prática do cálculo na lousa e no caderno (RAMBO, 1994, p. 157-158).

A partir do instrumento de análise de conteúdo construído com cinco unidades de análise e suas respectivas categorias, fundamentado em Bardin (2011) e descrito em Kuhn (2015), realiza-se a análise das duas edições da Segunda Aritmética.

\subsection{As operações de multiplicação e de divisão na Segunda Aritmética de Otto Goerl}

Na Segunda Aritmética de Otto Goerl o estudo das operações de multiplicação e de divisão é realizado através de situações contextualizadas. No excerto mostrado na Figura 1 se explora a ideia de multiplicação por 2 e por 10:

Figura 1: Multiplicação por 2 e por 10

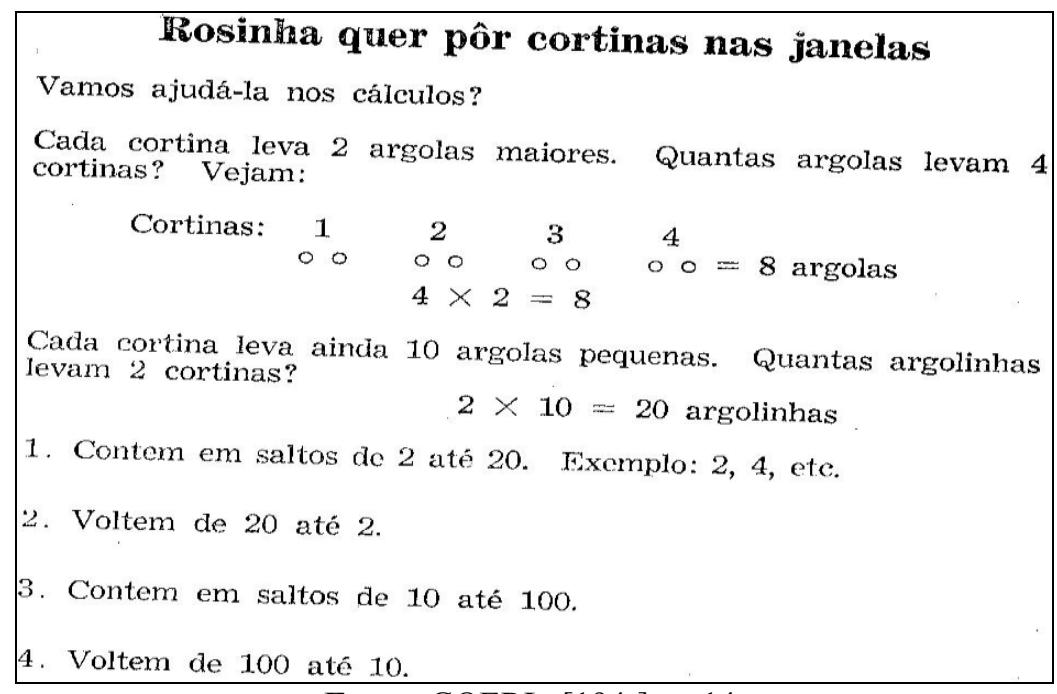

Fonte: GOERL, [194-], p. 14.

As multiplicações por 2 e por 10 são introduzidas no livro por meio de exemplos associados com argolas para prender cortinas em janelas, seguidos de exercícios com 
aplicação do conteúdo, conforme ilustrado na Figura 1. Destaca-se o uso da representação das argolas na sistematização da multiplicação por 2, o que possibilita ao aluno a visualização do processo. Também se observa a contagem até 20 em saltos de 2 e a contagem até 100 em saltos de 10, ambas em ordem crescente e descrente.

O autor continua a história das "cortinas de Rosinha" para desenvolver a ideia de multiplicação por 3 e por 5. Conforme Goerl [194-], para fazer uma cortina de Rosinha são necessários 3 m de fazenda, então, para fazer 3 cortinas são necessários 9 m $(3$ x $3=9)$. Cada cortina precisa de $5 \mathrm{~m}$ de corda, logo, 2 cortinas precisam de $10 \mathrm{~m}(2 \times 5=10)$. Nos exercícios explora a contagem até 50 em saltos de 5 e a contagem até 30 em saltos de 3 , ambas em ordem crescente e descrente. Os exercícios de contagem em saltos de 2, de 3, de 5 e de 10, na ordem crescente e decrescente, auxiliam o aluno na fixação dos múltiplos de 2, de 3 , de 5 e de 10, explorados nas história das "cortinas de Rosinha".

Na sequência, o autor traz a história "no Bazar Gaúcho" para explorar a ideia de divisão por 2 e por 3, conforme mostrado na Figura 2:

Figura 2: Divisão por 2 e divisão por 3

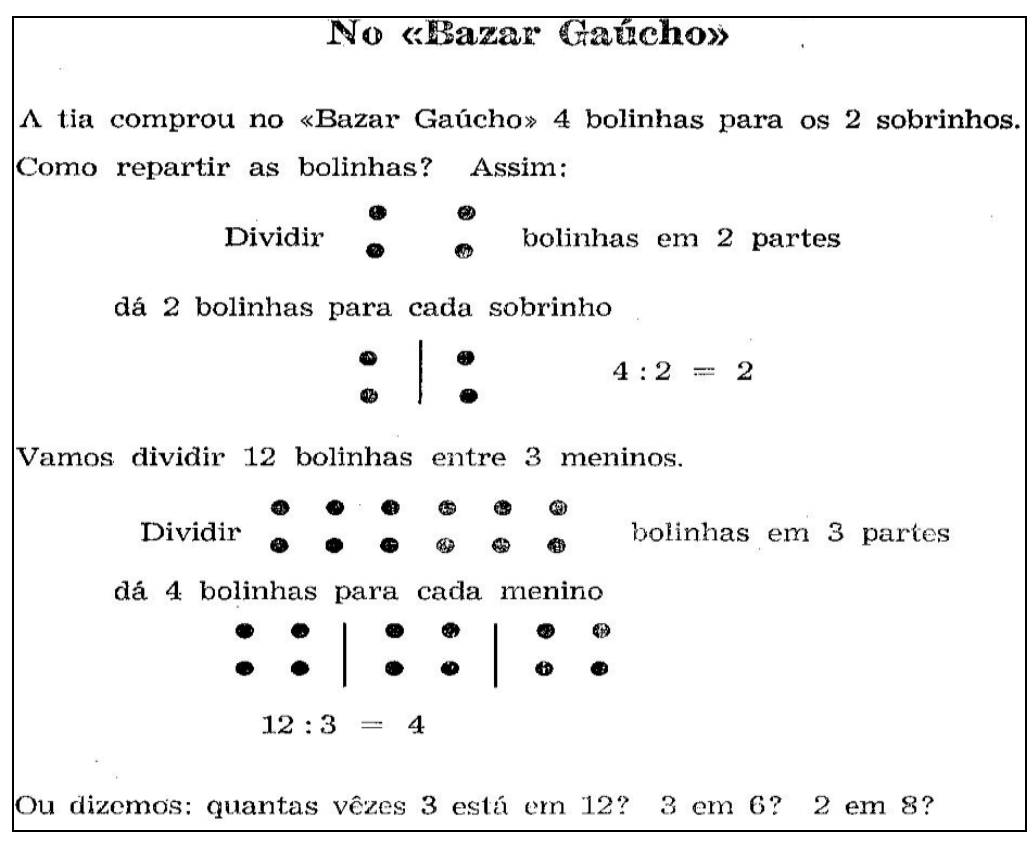

Fonte: GOERL, ..., [194-], p. 16.

Para desenvolver a ideia de repartir na divisão por 2 e na divisão por 3, o autor faz a representação da quantidade de bolinhas a serem repartidas entre os meninos e mostra a sua divisão em duas e três partes iguais, respectivamente. No final do excerto mostrado na Figura 2, o autor explora a ideia de medir da divisão através de perguntas. 
A história do "Bazar Gaúcho" é continuada para, além de desenvolver a divisão por 2 e por 3, também explorar a divisão por 10 e por 5 . O autor desenvolve essas divisões a partir dos preços unitários de mercadorias encontradas no bazar e questionando as quantidades de cada mercadoria que podem ser adquiridas com valores maiores, não ultrapassando $\mathrm{Cr} \$$ 100,00. Com o preço de uma borracha a Cr\$2,00, explora-se a divisão por 2; com o preço de um lápis a $\mathrm{Cr} \$ 3,00$, desenvolve-se a divisão por 3; a partir do preço de um copo a Cr\$ 10,00, explora-se a divisão por 10; com o preço de um caderno a $\operatorname{Cr} \$ 5,00$, desenvolve-se a divisão por 5 , neste caso "quantos cadernos compram-se por Cr\$10,00;20,00;30,00; 50,00; 15,00; 25,$00 ; 35,00 ; 45,00 ; 40,00$ ?" (GOERL, [194-], p. 17). Ressalta-se que os quocientes das divisões propostas são números naturais compreendidos entre 1 e 10.

Observa-se que a proposta da Segunda Aritmética de Otto Goerl desenvolve primeiro a multiplicação por 2 , por 3 , por 5 e por 10 , através da história das "cortinas de Rosinha", e depois explora a divisão por 2, por 3, por 5 e por 10 com as compras no "Bazar Gaúcho". Considerando o referencial da análise de conteúdo de Bardin (2011), o desenvolvimento da proposta pedagógica desta maneira subentende a ideia de que a multiplicação e a divisão são operações inversas. Essa ideia é reforçada no excerto mostrado na Figura 3, o qual explora a multiplicação e a divisão por 4 num mesmo contexto:

Figura 3: Multiplicação e divisão por 4

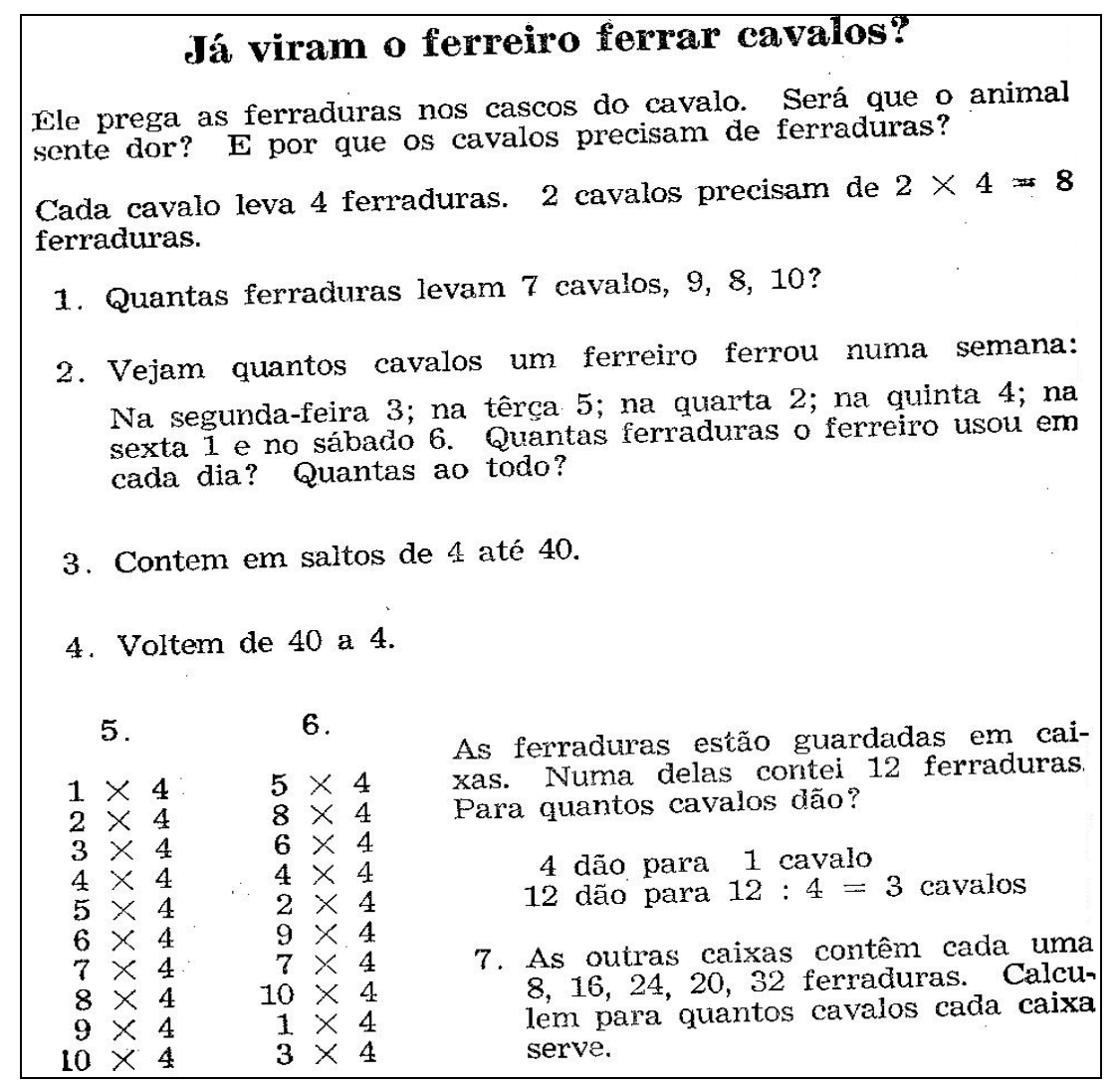

Fonte: GOERL, [194-], p. 18. 
A Figura 3 traz uma proposta do livro que questiona os alunos sobre a ação de colocar ferraduras em cavalos, envolvendo-os mais na atividade e assim, propondo o estudo da multiplicação por 4 e da divisão por 4 , associada a ideia de que cada cavalo precisa de 4 ferraduras. Propõem-se exercícios de contagem até 40 em saltos de 4, em ordem crescente e descrente, explorando-se a ideia dos múltiplos de 4. Na proposta dos exercícios 5 e 6 fíca subentendida a retomada da tabuada do 4. A "pequena tabuada", desenvolvida no primeiro ano de escolarização, era fixada no ano seguinte conforme Rambo (1994), justificando-se exercícios semelhantes no estudo da multiplicação por 2 até a multiplicação por 10 .

Em seguida, o autor propõe 12 "problemas mistos" associados a compras na "loja primavera". A partir dos preços de: $1 \mathrm{~m}$ de fita a $\mathrm{Cr} \$ 2,00 ; 1 \mathrm{dz}$ de botões a $\mathrm{Cr} \$ 5,00 ; 1 \mathrm{~m}$ de renda a $\mathrm{Cr} \$ 10,00 ; 1$ caixa de alfinetes a $\mathrm{Cr} \$ 4,00 ; 1 \mathrm{dz}$ de grampos a Cr\$3,00; exploram-se a multiplicação e a divisão por 2 , por 3 , por 4 , por 5 e por 10 , articuladas com as operações de adição ou de subtração para cálculo de troco para determinada quantia em dinheiro, como por exemplo: "Lia vai comprar $3 \mathrm{~m}$ de renda a Cr\$10,00 o metro. Ela paga com uma nota de 50 cruzeiros. Qual é o troco?” (GOERL, [194-], p. 19). Neste problema, o aluno desenvolve a operação de multiplicação, 3 x $10=30$, para então determinar o troco de Cr\$20,00, completando $\operatorname{Cr} \$ 50,00$ a partir dos $\operatorname{Cr} \$ 30,00$ do custo total da renda ou fazendo a subtração $50-30=20$.

Considerando-se as situações analisadas, ressalta-se que a proposta do livro é desenvolver os conhecimentos matemáticos de forma articulada com situações reais relacionadas ao cotidiano dos alunos, especialmente com operações comerciais e atividades desenvolvidas nas regiões coloniais do RS.

Ainda no contexto dos alunos, desenvolve-se a multiplicação e a divisão por 6 , partindo-se do horário semanal de aulas, conforme excerto mostrado na Figura 4:

Figura 4 - Multiplicação por 6

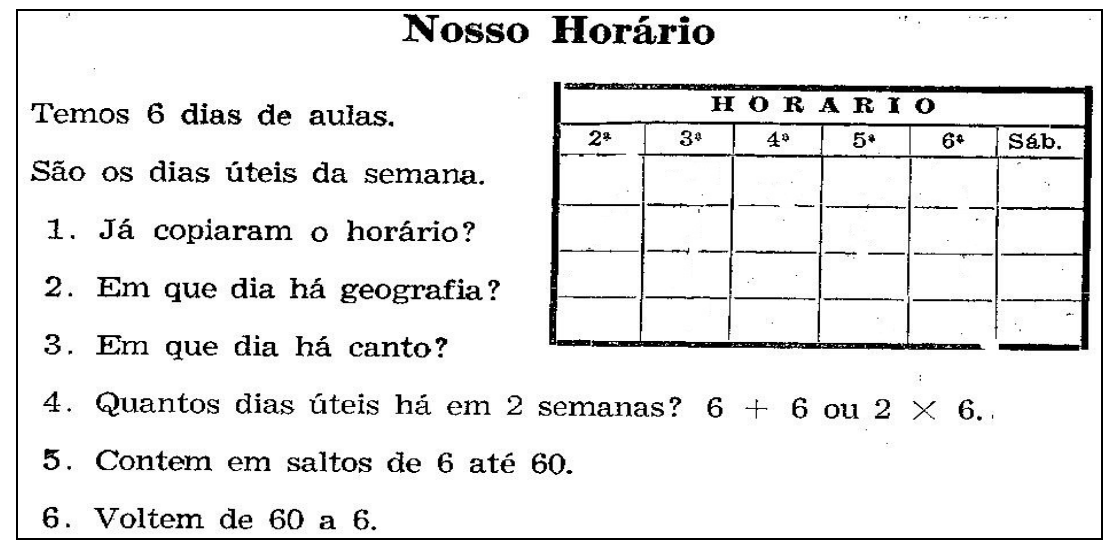

Fonte: GOERL, [194-], p. 22. 
De acordo com Rambo (1994), nessa época, a programação escolar cobria 6 dias da semana, com 4 horas diárias, perfazendo 24 horas semanais. Neste sentido, a proposta do livro parte do horário de aulas durante os 6 dias úteis da semana para desenvolver a ideia da multiplicação por 6. No exercício 4, para determinação do número de dias úteis em 2 semanas, apresenta-se a ideia de multiplicação como uma soma de parcelas iguais, ou seja, 6 $+6=2 \times 6$. Esta ideia não foi observada explicitamente nos estudos da multiplicação por 2, por 3 , por 4 , por 5 e por 10 , porém, começou a ser observada a partir do estudo da multiplicação por 6 .

Os exercícios propostos a partir da situação apresentada na Figura 4, exploram os múltiplos de 6 , a tabuada do 6 , a quantidade de dias úteis em mais semanas e a divisão por 6 como operação inversa da multiplicação. No desenvolvimento da multiplicação e da divisão por 6, o autor considerou os dias úteis da semana e no estudo da multiplicação e da divisão por 7, considerou a semana completa (7 dias), desenvolvendo um roteiro de estudo semelhante ao anterior, contextualizando este conhecimento matemático com uma unidade de medida de tempo, conhecida dos alunos.

A multiplicação e a divisão por 8 são exploradas através do serviço de um vidraceiro, conforme excerto apresentado na Figura 5:

Figura 5: Multiplicação e divisão por 8

O vidraceiro em servico
O vidraceiro coloca os vidros nas janelas. Sabem com que êle
corta o vidro?
Hoje o vidraceiro recebeu uma encomenda de uma escola para
janelas com 8 vidros cada uma. Ajudem a calcular o numero
de vidros em cada sala:
1. A secretaria tem 2 janelas: $2 \times 8=$
2. Cada classe tem 4 janelas.
3. A biblioteca tem 5 janelas.
4. O salão de festas tem 10 janelas.
5. A sala dos professôres tem 3 fanelas.
13. O vidraceiro compra os vidros em caixas. Numa caixa há 16
vidros. Para quantas janelas dão? $16: 8=$
14. Para quantas janelas dá cada caixa, contendo elas $24,48,32$,
56,40 vidros?

Fonte: GOERL, [194-], p. 24. 
A profissão de vidraceiro é explorada pelo autor para o estudo das operações de multiplicação e de divisão por 8 , num contexto de colocação de 8 vidros em cada janela dos diferentes ambientes de uma escola. Conforme Roche (1969), entre os imigrantes alemães haviam pessoas que exerciam diferentes profissões, embora tivessem que se dedicar inicialmente ao cultivo das terras, logo, começaram a surgir as profissões essenciais ao mundo rural, como pedreiro, mecânico, alfaiate, barbeiro, vidraceiro, entre outras.

Para o estudo da multiplicação e da divisão por 9, o autor faz uma associação com a venda de brinquedos num bazar e explora o jogo de bolão, o qual seria vendido em caixas com 9 paus cada. Além do jogo de bolão, explora-se a compra de outros objetos em quantidades que envolvem múltiplos de 9.

Após sistematizar o estudo das operações de multiplicação e de divisão até 10, recapitula-se a pequena tabuada e se propõe problemas sobre a multiplicação e a divisão, conforme exemplos apresentados no Quadro 1:

Quadro 1: Problemas envolvendo multiplicação e divisão ${ }^{4}$

17) Amélia foi comprar 6 metros de renda a $\mathrm{Cr} \$ 4,00$ o $\mathrm{m}$ e 10 botões grandes a $\mathrm{Cr} \$$ 2,00 cada um. Quanto gastou?

18) A vaca de Da. Rita está dando 8 litros de leite por dia. Quantos litros dá por semana?

19) Se 3 pessoas levam 6 dias para capinar uma roça de milho, quantos dias levaria 1 pessoa só para fazer o mesmo serviço? (p. 27).

10) Paulo foi contanto os ovos que as 9 galinhas estavam pondo. No fim da semana eram 36 ovos. Quantos ovos tocavam a cada galinha?

11) O tio gasta $7 \mathrm{~kg}$ de alfafa por dia com os seus cavalos. Para quantos dias dará um fardo de $45 \mathrm{~kg}$ que o tio comprou? (p. 29).

Fonte: GOERL,[194-].

Os três primeiros problemas mostrados no Quadro 1 envolvem a operação de multiplicação até 10 e os outros dois problemas estão relacionados com a operação de divisão, sendo que o último envolve uma divisão não exata. Os problemas propostos são uma aplicação dos conteúdos abordados e estão contextualizados com práticas socioculturais das comunidades em que as escolas paroquiais luteranas estavam inseridas.

$\mathrm{Na}$ sequência, o autor do livro apresenta os termos da operação de multiplicação, desenvolve a multiplicação com dezenas, enfatizando a multiplicação por 10 e por 100 e introduz a multiplicação com dezenas e unidades, através do exemplo mostrado no Quadro 2:

\footnotetext{
${ }^{4}$ Neste artigo se optou por manter a numeração dos problemas conforme as fontes originais da série Concórdia.
} 
Quadro 2: Multiplicação com dezenas mistas

\begin{tabular}{|ll|}
\hline $8 \times 15$ & $8 \times 10=80$ \\
$8 \times 5$ & $=40$ \\
&
\end{tabular}

Fonte: GOERL, [194-], p. 59.

Observa-se que a proposta apresentada para multiplicação com dezenas e unidades é fazer a decomposição da dezena mista em dezenas e unidades $(15=10+5)$, para efetuar as multiplicações separadamente $(8 \times 10$ e 8 × 5) e somar os produtos parciais $(80+40)$ para chegar ao produto (120). Após este exemplo, propõem-se exercícios de aplicação com multiplicações envolvendo dezenas mistas até 99.

Na Figura 6 se apresenta um excerto com o título "o tempo na multiplicação":

Figura 6: O tempo na multiplicação

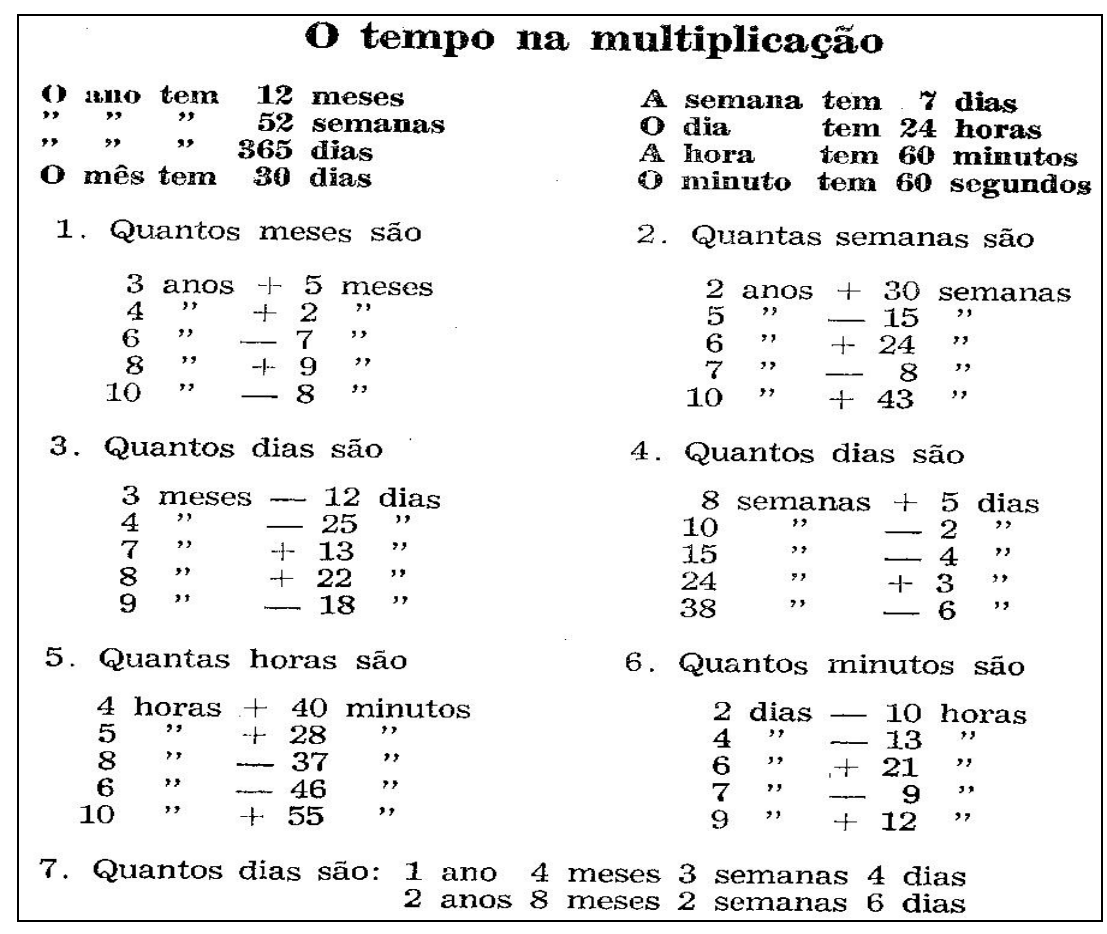

Fonte: GOERL, [194-], p. 60.

No estudo da multiplicação e da divisão por 6 e por 7, Goerl [194-] fez associações com os dias úteis da semana e com a semana completa, respectivamente. A proposta de estudo apresentada na Figura 6 explora relações entre as unidades de medida de tempo (anos, meses, semanas, dias, horas e minutos) associadas à operação de multiplicação e ainda às operações de adição ou de subtração. O exercício 7 , por exemplo, pode ser resolvido da seguinte maneira: 
a) 1 ano 4 meses 3 semanas 4 dias $=1 \times 365$ dias $+4 \times 30$ dias $+3 \times 7$ dias +4 dias $=$ 365 dias +120 dias +21 dias +4 dias $=510$ dias.

b) 2 anos 8 meses 2 semanas 6 dias $=2 \times 365 \operatorname{dias}+8 \times 30 \operatorname{dias}+2 \times 7$ dias $+6 \operatorname{dias}=$ 730 dias +240 dias +14 dias +6 dias $=990$ dias.

Neste caso, as transformações das unidades de medida de tempo são realizadas usando-se as operações de multiplicação e de adição.

O autor também apresenta os termos da operação de divisão no livro, explora a divisão com um ou mais zeros no dividendo e a divisão por 10. Em seguida, apresenta um algoritmo para divisão, conforme exposto no Quadro 3:

Quadro 3: Algoritmo para divisão

\begin{tabular}{|c|c|c|c|}
\hline \multicolumn{4}{|c|}{ Como dividir $52 \div 3 ?$} \\
\hline \multirow[t]{3}{*}{ Assim: } & $52 \div 3=$ & $30 \div 3=$ & 10 \\
\hline & & $22 \div 3=$ & 7 resto 1 \\
\hline & & & 17 resto 1 \\
\hline
\end{tabular}

Fonte: GOERL, [194-], p. 63.

O algoritmo para divisão mostrado no Quadro 3 propõe a decomposição do dividendo (52) em dezenas simples (30) e dezenas mistas (22), procurando-se obter a maior divisão exata com as dezenas simples, para efetuar as divisões separadamente $(30 \div 3$ e $22 \div 3)$ e somar os quocientes parciais $(10+7)$ para chegar ao quociente (17) e resto (1). Após este exemplo, propõem-se exercícios envolvendo a operação de divisão, chamando atenção que o autor relaciona a divisão por 12 com dúzias $(1$ dúzia $=12)$ e a divisão por 15 com arrobas (1 arroba $=15$ quilos).

Embora predomine uma proposta de estudo das operações de multiplicação e de divisão de forma contextualizada na Segunda Aritmética de Otto Goerl, observaram-se também exercícios para o desenvolvimento de habilidades de cálculo mental e de cálculo escrito com o algoritmo na horizontal.

\subsection{As operações de multiplicação e de divisão na Segunda Aritmética de 1948}

A Segunda Aritmética de 1948 não desenvolve a ideia de multiplicação e de divisão por 2 até 10 como a Segunda Aritmética de Goerl [194-]. Apenas é proposto um exercício para retomada da pequena tabuada nas primeiras páginas do livro. Em seguida, exploram-se as operações de multiplicação e de divisão com centenas e dezenas de acordo com o excerto mostrado no Quadro 4: 
Quadro 4: Multiplicação e divisão com centenas e dezenas

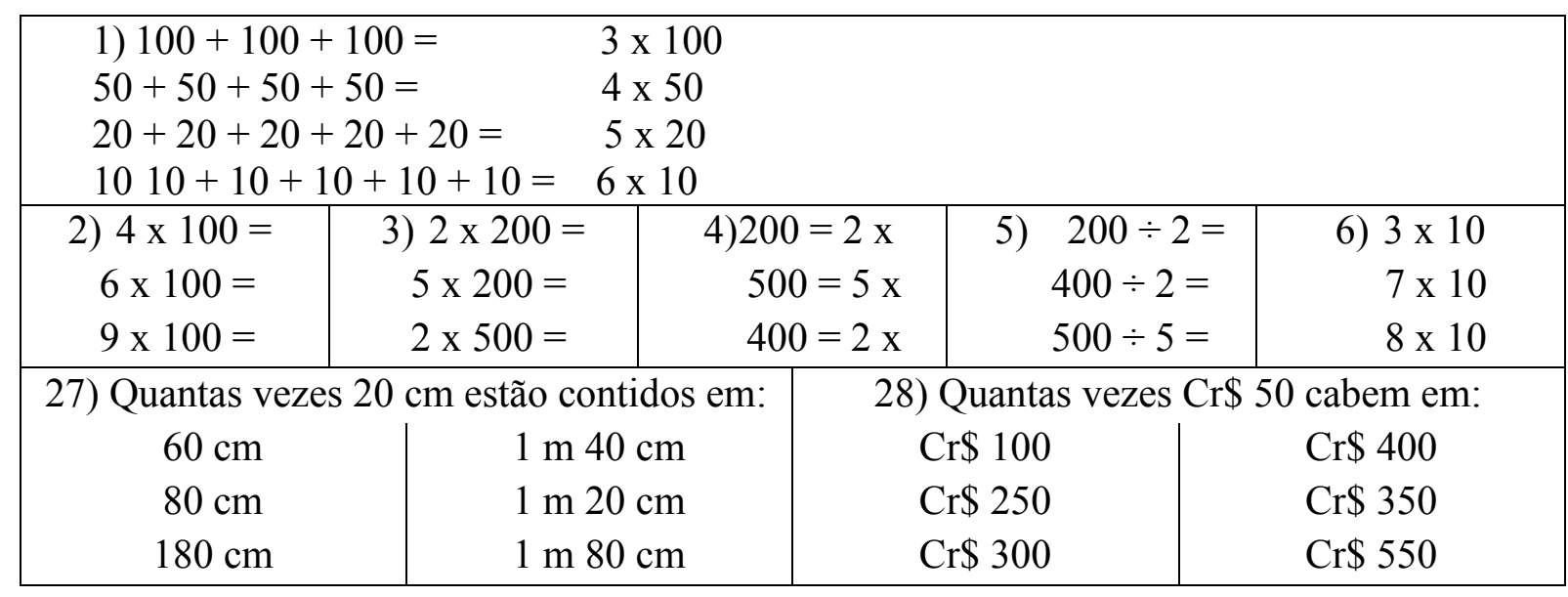

Fonte: SÉRIE ..., 1948, p. 37-38.

No exercício 1 observado no Quadro 4, o livro desenvolve a ideia de multiplicação como uma soma de parcelas iguais para multiplicações por 10, por 20, por 50 e por 100. Essa ideia de multiplicação foi pouco explorada por Goerl [194-], encontrando-se registros da mesma no estudo das multiplicações por 6, por 7 e por 9. Além da operação de multiplicação, neste excerto se desenvolve a ideia de medir da divisão, relacionando-a com unidades de medida de comprimento no exercício 27 e com o sistema monetário no exercício 28. Verificou-se uma quantidade significativa de exercícios orais e escritos envolvendo as operações de multiplicação e de divisão na Segunda Aritmética de 1948. Lindemann (1888) defendia propostas de ensino com exercícios para o desenvolvimento de habilidades de cálculo escrito e de cálculo oral de acordo com o nível dos alunos, partindo do simples para o complexo e retomando conteúdos estudados previamente.

A Segunda Aritmética de 1948 apresenta propostas de estudo semelhantes àquela mostrada no Quadro 4 para o desenvolvimento das multiplicações e das divisões por 30, 40, 60, 70, 80 e 90, explorando a multiplicação como uma soma de parcelas iguais e a divisão como uma medida. A multiplicação com dezenas mistas na Segunda Aritmética de 1948 é introduzida pelo exemplo:

$3 \times 24=60+12=72$

Observa-se que, no algoritmo apresentado no exemplo, fica subentendida a decomposição da dezena mista em dezenas e unidades $(24=20+4)$, para efetuar as multiplicações separadamente $(3 \times 20$ e $3 \times 4)$ e somar os produtos parciais $(60+12)$ para chegar ao produto final (72). Essa ideia é reforçada com exercícios semelhantes ao exemplo apresentado.

A operação de divisão com dezenas mistas é desenvolvida a partir do exemplo: 


$$
72 \div 3=20+4=24
$$

Verifica-se que, no algoritmo para divisão apresentado no exemplo, fica subentendida a decomposição do dividendo (72) em dezenas simples (60) e dezenas mistas (12), procurando-se obter a maior divisão exata com as dezenas simples, para efetuar as divisões separadamente $(60 \div 3$ e $12 \div 3)$, somar os quocientes parciais $(20+4)$ e chegar ao quociente (24). Após este exemplo, propõem-se exercícios envolvendo a operação de divisão para aplicação do algoritmo desenvolvido.

Ressalta-se que, com os exemplos apresentados para a multiplicação, 3 x $24=72$, e para a divisão, $72 \div 3=24$, a proposta do livro é desenvolver a ideia de que a multiplicação e a divisão são operações inversas. De acordo com Gans (2013, apud Kuhn, 2015), no $3^{\circ}$ ano de escolarização nas escolas paroquiais luteranas, focava-se a ideia de operações inversas nos cálculos de multiplicação e de divisão. Além disto, verificou-se que as duas edições da Segunda Aritmética trazem uma proposta de estudo para a multiplicação e para a divisão de dezenas mistas com algoritmos semelhantes, propondo a decomposição da dezena mista.

No Quadro 5 se apresentam problemas que envolvem as operações de multiplicação e de divisão com dezenas mistas:

Quadro 5: Problemas envolvendo multiplicação e divisão com dezenas mistas

23) Quantos kg de banha há em 7 latas, pesando cada lata $18 \mathrm{~kg}$ ?

24) Nós temos 24 horas de ensino por semana; quantas horas de ensino teremos em 3 , $4,7,2,6$ semanas?

28) O preço de uma Bíblia é de Cr\$16,00. Vendem-se 8 Bíblias a 8 alunos. (p. 45).

25) Por 6 sacos de feijão recebemos Cr\$108,00. Quer-se saber o preço de 1 saco.

27) A conta de leite de 6 meses importa em Cr\$168,00. Quer-se saber a quanto sai por mês.

30) Sabendo-se que 8 sacos de feijão pesaram $480 \mathrm{~kg}$, qual será o peso de cada saco? (p. 47).

\section{Fonte: SÉRIE ..., 1948.}

Os três primeiros problemas mostrados no Quadro 5 estão relacionados com a operação de multiplicação com dezenas mistas. Resolvendo-se o problema 23, a partir da ideia de decomposição da dezena mista acima exposta, tem-se:

$7 \times 18=7 \times 10+7 \times 8=70+56=126$

Então, 7 latas de banha totalizam $126 \mathrm{~kg}$. 
Os outros três problemas apresentados no Quadro 5 envolvem a operação de divisão com centenas mistas. Partindo da ideia de decomposição, o problema 25 pode ser resolvido da seguinte maneira:

$$
\begin{aligned}
& 108 \div 6=90 \div 6+18 \div 6=15+3=18 \text { ou } \\
& 108 \div 6=60 \div 6+48 \div 6=10+8=18
\end{aligned}
$$

Portanto, o preço de 1 saco de feijão é Cr\$ 18,00.

Depois de explorar o algoritmo para multiplicação e para divisão na horizontal, a Segunda Aritmética de 1948 apresenta os algoritmos na vertical (por escrito) para estas operações. No Quadro 6, observa-se que o livro apresenta os algoritmos para multiplicação por escrito, desenvolvendo quatro casos:

\begin{tabular}{|c|c|c|}
\hline \multicolumn{3}{|c|}{ 1) O multiplicador é um número de 1 algarismo. } \\
\hline 826 & 963 & Nota: $10 \mathrm{U}=1 \mathrm{D}$ \\
\hline$\times \quad 4$ & $\times \quad 7$ & $10 \mathrm{D}=1 \mathrm{C}$ \\
\hline 3304 & 6741 & $10 \mathrm{C}=1 \mathrm{M}$ \\
\hline \multicolumn{3}{|c|}{ 2) O multiplicador é uma dezena. } \\
\hline \multirow{3}{*}{$80=8 \times 10$} & 87 & Multiplica-se primeiro pelo número da \\
\hline & $\underline{\mathrm{X} 30}$ & dezena. Depois multiplica-se por 10 , \\
\hline & 2610 & acrescentando um zero. \\
\hline \multicolumn{3}{|c|}{ 3) O multiplicador é uma centena. } \\
\hline \multirow{3}{*}{$\begin{array}{l}300=3 \times 100 \\
700=7 \times 100\end{array}$} & 89 & Multiplica-se primeiro pelo número da \\
\hline & $\underline{\times} 600$ & centena. Depois multiplica-se por 100 , \\
\hline & 53400 & acrescentando dois zeros. \\
\hline \multicolumn{3}{|c|}{ 4) O multiplicador é um número de dois algarismos. } \\
\hline \multicolumn{2}{|c|}{38} & Multiplica-se primeiro pelo número da \\
\hline \multicolumn{2}{|c|}{$\underline{\mathrm{x} 58}$} & unidade. Depois multiplica-se pelo número \\
\hline \multicolumn{2}{|c|}{288} & da dezena. Ao fim, soma-se as parcelas. \\
\hline \multicolumn{2}{|c|}{180} & \\
\hline \multicolumn{2}{|c|}{2088} & \\
\hline
\end{tabular}

Quadro 6: Multiplicação por escrito

Fonte: SÉRIE ..., 1948, p. 84-85.

No primeiro caso, em que o multiplicador é um número de um algarismo, o livro apresenta uma nota informativa sobre a relação entre unidades e dezena, dezenas e centena, centenas e milhar, e dois exemplos sem detalhar o procedimento de cálculo. Nos casos em que o multiplicador é uma dezena ou uma centena, o livro explora o procedimento de cálculo valendo-se de regras da multiplicação por 10 e por 100, respectivamente. Quando o 
multiplicador é um número de dois algarismos, o livro sistematiza o procedimento de cálculo e apresenta um exemplo.

Na Segunda Aritmética de Goerl [194-] foram encontradas as provas reais para as operações de adição e de subtração, enquanto que na Segunda Aritmética de 1948 foram observadas as provas reais para as quatro operações com os números naturais. No Quadro 7 se apresentam as provas reais para a operação de multiplicação:

Quadro 7: Provas reais para multiplicação

\begin{tabular}{|c|c|}
\hline $\begin{array}{l}1^{a} \text { prova: Inverter a ordem dos fatores, isto é, tomar o } \\
\text { multiplicando como multiplicador e o multiplicador como } \\
\text { multiplicando. Se o resultado da prova for o mesmo que o } \\
\text { da multiplicação, é muito provável, que a operação esteja } \\
\text { exata. }\end{array}$ & 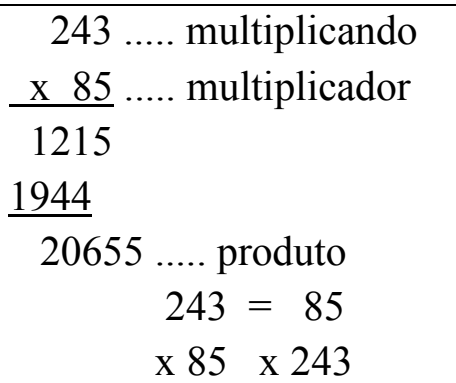 \\
\hline $\begin{array}{l}2^{\mathrm{a}} \text { prova: Dividindo o produto por um dos fatores, } \\
\text { deve-se obter o outro fator. }\end{array}$ & 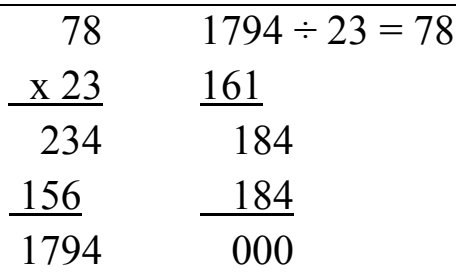 \\
\hline $\begin{array}{l}3^{\text {a }} \text { prova: ( } 9 \text { fora) Traçar duas linhas que se cortem } \\
\text { em forma de X; depois tiram-se os } 9 \text { fora do } \\
\text { multiplicando e escreve-se o resto no ângulo superior da } \\
\text { cruz. Tiram-se os } 9 \text { fora do multiplicador, e escreve-se o } \\
\text { resto no ângulo inferior da cruz. Multiplicam-se os dois } \\
\text { restos, do número que sai e tiram-se os } 9 \text { fora e escreve-se } \\
\text { o resto no ângulo direito da cruz. Enfim, tiram-se os } 9 \\
\text { fora do produto, e escreve-se o resto no ângulo esquerdo. } \\
\text { Se o resto igualar ao que lhe fica oposto, pode-se }\end{array}$ & $\begin{array}{r}358 \ldots .7 \\
47 \ldots . . \\
2506 \\
\frac{1432}{16826} \ldots . .5\end{array}$ \\
\hline
\end{tabular}

Fonte: SÉRIE ..., 1948, p. 90.

O livro aborda três provas reais para a operação de multiplicação, apresentando-se os algoritmos e os procedimentos para realização da prova real em multiplicações. A $1^{\mathrm{a}}$ prova consiste em inverter a ordem dos fatores para verificar o produto. A $2^{\mathrm{a}}$ prova envolve a divisão como operação inversa da multiplicação e a $3^{a}$ prova é dos 9 fora, conforme descrito no Quadro 7.

A Segunda Aritmética de 1948 ainda traz as provas para a operação de divisão, conforme apresentado no Quadro 8: 
Quadro 8: Provas reais para divisão

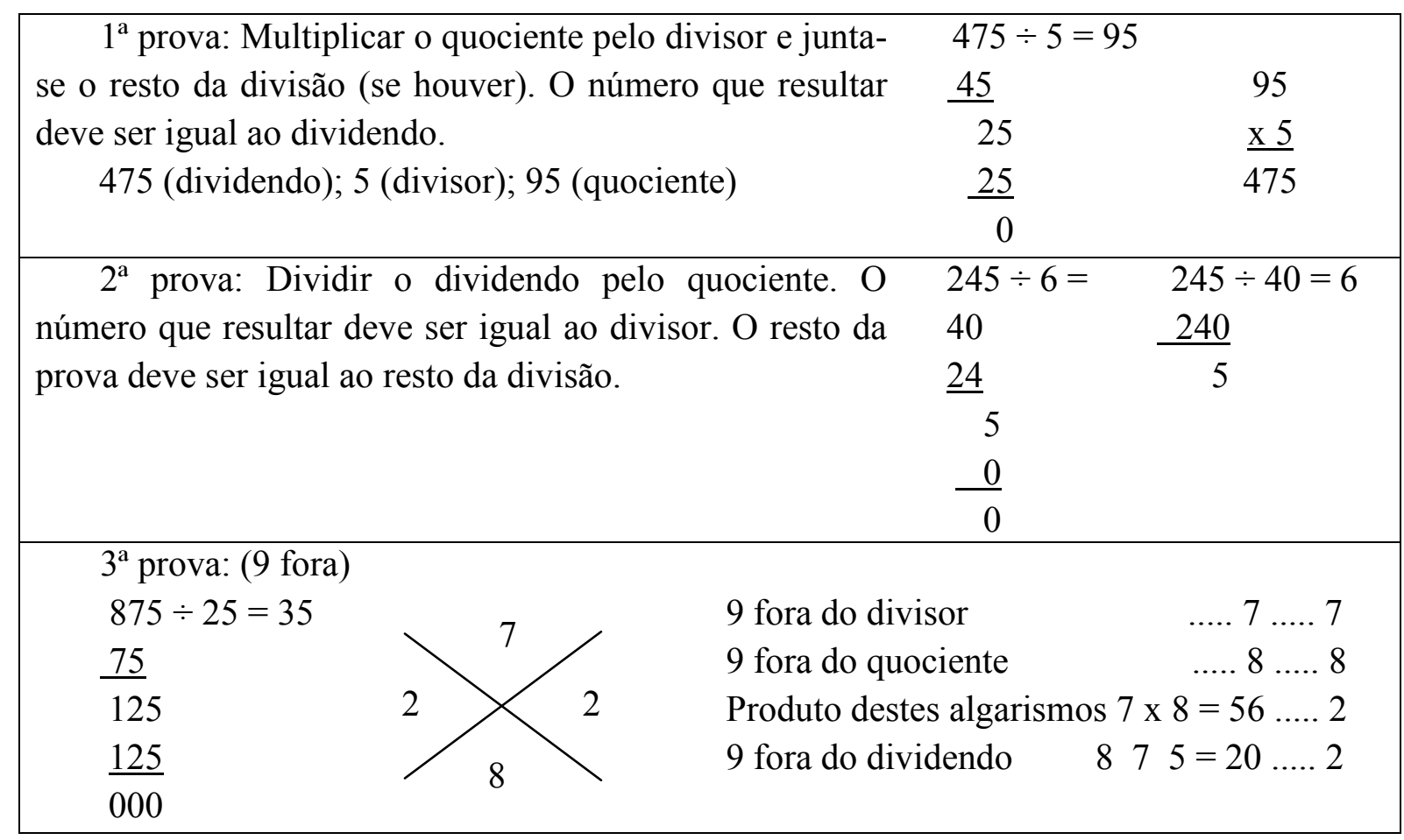

Fonte: SÉRIE ..., 1948, p. 91.

O Quadro 8 mostra como o livro aborda as três provas reais para a operação de divisão, apresentando-se os algoritmos e os procedimentos para realização da prova real em divisões. A $1^{\mathrm{a}}$ prova envolve a multiplicação como operação inversa da divisão. A $2^{\mathrm{a}}$ prova consiste em dividir o dividendo pelo quociente obtido, devendo-se obter um resultado igual ao divisor e os restos da prova e da divisão devem ser iguais. A $3^{\text {a }}$ prova é dos 9 fora, conforme descrito no quadro acima.

A partir das três provas de multiplicação e de divisão apresentadas, ressalta-se que a proposta da Segunda Aritmética de 1948 enfatiza os algoritmos e os procedimentos para verificação da prova real de cada operação matemática, na intenção de desenvolver habilidades nos alunos para o cálculo escrito e o cálculo mental.

\section{Considerações finais}

A partir dos referenciais da história cultural e da análise de conteúdo, investigaram-se as propostas de ensino para as operações de multiplicação e de divisão, analisando-se as duas edições da Segunda Aritmética da série Concórdia, editadas pela IELB para suas escolas paroquiais gaúchas, na primeira metade do século XX. Verificou-se que as duas aritméticas apresentam conhecimentos matemáticos com ênfase nas operações de multiplicação e de divisão com números naturais. 
A Segunda Aritmética de Otto Goerl desenvolve as ideias de multiplicação e de divisão, por 2 até 10 , de forma contextualizada com práticas socioculturais comuns nas comunidades em que as escolas paroquiais luteranas estavam inseridas. Nesta proposta de estudo se explorou a ideia da multiplicação como uma soma de parcelas iguais e as ideias de repartir e de medir na operação de divisão. Além disto, verificaram-se atividades de ensino para compreensão da multiplicação e da divisão como operações inversas. O estudo dessas operações se amplia para cálculos com dezenas e centenas, predominando o algoritmo na horizontal e explorando a decomposição da dezena mista ou da centena mista.

A Segunda Aritmética de 1948 faz uma retomada da pequena tabuada e, em seguida, exploram-se as operações de multiplicação e de divisão com dezenas e centenas, desenvolvendo-se a multiplicação como uma soma de parcelas iguais e a divisão como uma medida. Verifica-se uma proposta de estudo inicial para a multiplicação e para a divisão com o algoritmo na horizontal, explorando-se a ideia de decomposição da dezena mista ou da centena mista, com aplicação em problemas relacionados a práticas sociais e o cotidiano dos alunos. Na sequência, a proposta do livro desenvolve o algoritmo vertical para a multiplicação e a divisão, apresentando inclusive, as provas reais para essas operações.

Ao finalizar esta investigação, aponta-se que, embora predomine uma proposta de estudo das operações de multiplicação e de divisão de forma mais contextualizada na Segunda Aritmética de Otto Goerl, as duas aritméticas trazem atividades para o desenvolvimento de habilidades de cálculo mental e de cálculo escrito, com foco nos algoritmos e procedimentos de cálculo das operações de multiplicação e de divisão.

\section{Referências}

BARDIN, Laurence. Análise de conteúdo. Tradução de Luís Antero Reto e Augusto Pinheiro. São Paulo: Edições 70, 2011.

CHERVEL, André. História das disciplinas escolares - reflexões sobre um campo de pesquisa. Teoria \& Educação, Porto Alegre, n. 2, p. 177-229, 1990.

GOERL, Otto A.. Série Concórdia: Segunda Aritmética. Porto Alegre: Casa Publicadora Concórdia, [194-].

JULIA, Dominique. A cultura escolar como objeto histórico. Revista Brasileira de História da Educação, Campinas, n. 1, p. 9-43, jan./jun. 2001.

KUHN, Malcus Cassiano. $O$ ensino da matemática nas escolas evangélicas luteranas do Rio Grande do Sul durante a primeira metade do século XX. 2015. 466 f. Tese (Doutorado em Ensino de Ciências e Matemática) - Universidade Luterana do Brasil, ULBRA, Canoas, 2015. 
LEMKE, Marli Dockhorn. Os princípios da educação cristã luterana e a gestão de escolas confessionárias no contexto das ideias pedagógicas no sul do Brasil (1824 - 1997). Canoas: Ed. ULBRA, 2001.

LINDEMANN, Johann Christoph Wilhelm. Amerikanisch-Lutherische Schul-Praxis. 2. ed. Sant Louis: Lutherischer Concordia - Verlag, 1888.

RAMBO, Arthur Blásio. A Escola comunitária teuto-brasileira católica. São Leopoldo: Ed. Unisinos, 1994.

ROCHE, Jean. A Colonização Alemã e o Rio Grande do Sul. Porto Alegre: Editora Globo, 1969. v. 1 e v. 2.

SÉRIE Concórdia: Segunda Aritmética. Porto Alegre: Casa Publicadora Concórdia, 1948.

UNSERE SCHULE. Porto Alegre: Casa Publicadora Concórdia, 1933-1935.

WARTH, Carlos Henrique. Crônicas da Igreja: Fatos Históricos da Igreja Evangélica Luterana do Brasil (1900 a 1974). Porto Alegre: Concórdia, 1979.

WEIDUSCHADT, Patrícia. O Sínodo de Missouri e a educação pomerana em Pelotas e São Lourenço do Sul nas primeiras décadas do século XX: identidade e cultura escolar. 2007. 255 f. Dissertação (Mestrado em Educação) - Universidade Federal de Pelotas, Pelotas, 2007. 